\title{
GEOQUÍMICA DAS ÁGUAS DA BACIA HIDROGRÁFICA DO RIO DESCOBERTO, BRASÍLIA/DF - BRASIL
}

Marciléia Silva do Carmo*

Centro de Geociências, Universidade Federal do Pará, Rua Augusto Corrêa, 1, 66075-950 Belém - PA

Geraldo Resende Boaventura

Instituto de Geociências, Universidade de Brasília, 70910-900 Brasília - DF

Edivan Costa Oliveira

Coordenação de Química, Centro Federal de Educação Tecnológica do Pará, Av. Almirante Barroso,1155, 66093-020 Belém - PA

Recebido em 13/10/03; aceito em 25/2/05; publicado na web em 25/5/05

\begin{abstract}
GEOCHEMISTRY OF THE WATERS OF THE DESCOBERTO RIVER HYDROGRAPHIC BASIN, BRASÍLIA/DF - BRAZIL. The objective of this paper is to investigate the physical and chemical quality of the water of the Descoberto River during the dry and rainy seasons by measuring $\mathrm{pH}$, temperature, electric conductivity, total dissolved solids, turbidity, color, alkalinity and $\mathrm{NO}_{3}^{-}$, $\mathrm{SO}_{4}^{2-}, \mathrm{PO}_{4}^{3-}, \mathrm{NH}_{4}^{+}, \mathrm{Cl}^{-}$and $\mathrm{HCO}_{3}^{-}$, and the elements $\mathrm{Sr}, \mathrm{Mo}, \mathrm{Cd}, \mathrm{Y}, \mathrm{Ti}, \mathrm{Ca}, \mathrm{V}, \mathrm{Mg}, \mathrm{Fe}, \mathrm{Si}, \mathrm{Ni}, \mathrm{Zr}, \mathrm{Cu}, \mathrm{Al}, \mathrm{Cr}, \mathrm{Mn}, \mathrm{Ba}, \mathrm{Co}, \mathrm{Zn}, \mathrm{P}, \mathrm{Na}$ and $\mathrm{K}$. The results showed high concentrations in both seasons, with dilution along the course of the river, minimizing for a while problems that compromise the quality of the water of this source. However, a progressive deterioration can occur due to an increase in the discharge of pollutants, resulting from population growth, agricultural activities and other factors.
\end{abstract}

Keywords: Descoberto River; Distrito Federal; geochemistry of waters.

\section{INTRODUÇÃO}

A Bacia Hidrográfica do Rio Descoberto (BHRD), localizada entre as latitudes $15^{\circ} 36^{\prime} 00^{\prime \prime} \mathrm{S}$ e $16^{\circ} 05^{\prime} 00^{\prime \prime} \mathrm{S}$ e as longitudes $48^{\circ} 18^{\prime} 00^{\prime \prime} \mathrm{W}$ e $48^{\circ} 06^{\prime} 00^{\prime}$ ' W, possui uma área de $895,9 \mathrm{~km}^{2}$, onde o rio percorre toda a porção oeste do Distrito Federal (DF).

O Rio Descoberto (RD) recebe descargas distintas de poluentes, entre as quais se destacam os efluentes domésticos, o deflúvio superficial urbano e o agrícola.

O principal afluente do RD, o Rio Melchior, recebe sem tratamento as descargas domésticas das cidades-satélites de Taguatinga, Ceilândia, Águas Claras e Samambaia ${ }^{1}$. Esta carga de material atinge o RD na porção sul, próximo à cidade de Santo Antônio do Descoberto, divisa com o estado de Goiás.

Vários trabalhos já foram realizados em alguns mananciais do DF, por Boaventura et al. ${ }^{2-6}$, mostrando, respectivamente, a evolução geoquímica da água na Bacia do Gama, Bananal, Taquara, São Bartolomeu e do Rio Descoberto.

As práticas que comprometem a qualidade da água de bacias hidrográficas, principalmente aquelas destinadas ao abastecimento público, são o uso indiscriminado de fertilizantes, agrotóxicos e pesticidas em áreas de atividade agrícola e o despejo de efluentes domésticos ${ }^{7-11}$.

A distribuição e disponibilidade de elementos químicos dependem não só das suas concentrações, mas de suas associações químicas e físicas nos sistemas naturais, influenciados pelas condições ambientais, intemperismo natural e/ou ações antrópicas.

Estudos em sistemas fluviais apontaram como possível fonte dos elementos $\mathrm{Ni}, \mathrm{Cr}, \mathrm{Cu}, \mathrm{Fe}, \mathrm{Al}, \mathrm{Mn}, \mathrm{Ca}, \mathrm{Mg}, \mathrm{K}$ e $\mathrm{Zn}$ a ocupação do solo através da urbanização, o mesmo ocorrendo em áreas cultivadas ${ }^{12-14}$. Constataram também que $\mathrm{Mn}, \mathrm{Zn}$ e $\mathrm{Cu}$ são provenientes, principalmente, de fertilizantes ${ }^{12}$.

Este estudo tem o objetivo de caracterizar física e quimicamente as águas para uma avaliação das possíveis fontes de conta-

*e-mail: marcileia@ufpa.br minação e suas consequiências a médio e longo prazo, visto que o RD é afluente do Rio Corumbá, onde existe um projeto de construção em andamento de uma barragem para futura geração de energia e abastecimento do DF e áreas cincunvizinhas.

\section{Localização e caracterização da área}

A área da bacia encontra-se situada no DF e no estado de Goiás, entre as coordenadas UTM (Universal Transversa de Mercator), norte 8.271 .000 e 8.225 .000 e leste 791.000 e 814.000 (Figura 1), possui como limite à leste o Lago de Santa Maria, onde está localizado o Parque Nacional de Brasília; a oeste a Bacia do Rio Verde, onde estão os municípios goianos de Santo Antônio do Descoberto e Padre Bernardo; ao norte a Bacia do Rio Maranhão e ao sul a subbacia do Rio Melchior.

O RD abastece atualmente $70 \%$ da população do $\mathrm{DF}^{15}$. Nasce a $1.300 \mathrm{~m}$ de altitude na região noroeste do Distrito Federal, desenvolvendo-se inicialmente nos contrafortes da Chapada da Veredinha no Planalto Central e segue na direção NW, após a confluência de seus formadores: os córregos Capão da Onça e Bucanhão ${ }^{16}$.

O RD flui posteriormente na direção sul, onde entra na região de influência do remanso provocado pelo barramento do Lago Descoberto. Para o Lago contribuem os córregos Pulador e Olaria, que são próximos à cidade de Brazlândia (cidade basicamente agrícola), o Ribeirão Rodeador, o Capão Comprido e o Ribeirão das Pedras. Entre Rodeador e Capão Comprido, localiza-se a Colônia Alexandre Gusmão (INCRA) responsável pela produção de $40 \%$ dos produtos hortifrutigranjeiros consumidos no $\mathrm{DF}^{17}$. A maioria dos produtores rurais que trabalham na colônia, prepara os terrenos para o plantio sem os cuidados necessários, retirando a faixa de vegetação (mata ciliar) dos percursos d'água e usando agrotóxicos no cultivo dos hortifrutigranjeiros várias vezes ao ano ${ }^{18}$.

Continuando o percurso na direção sul, o RD recebe contribuição dos Córregos Chapadinha, Bocaina e Dois Irmãos, sendo que nesta área existem muitas chácaras com plantio de hortaliças. Logo adiante encontra-se com seu principal afluente, o Rio Melchior, 


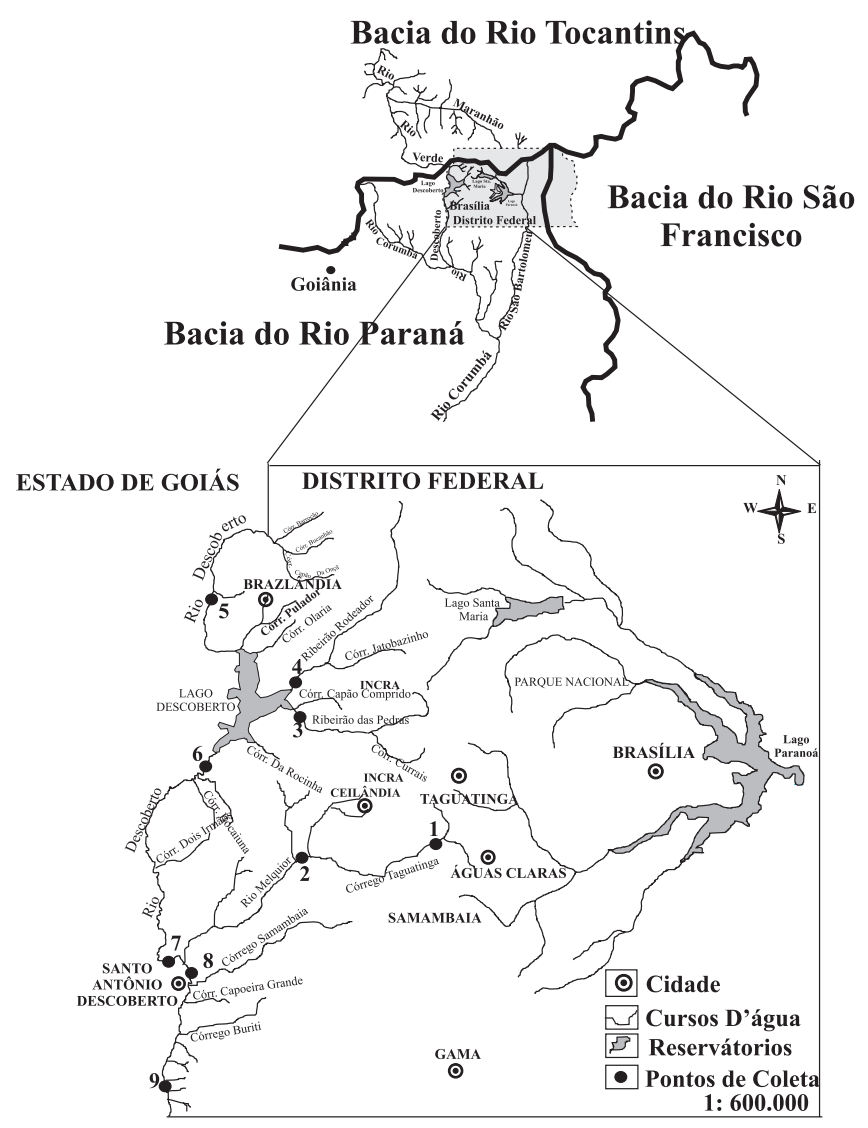

Figura 1. Localização da Bacia do Rio Descoberto e dos pontos de amostragem

que possui no seu mesmo braço formador o Córrego Taguatinga. Este córrego recebe esgoto sem tratamento das cidades-satélites de Taguatinga, Ceilândia, Samambaia e Águas Claras. Mais à frente, o Rio Descoberto encontra-se com o Rio Corumbá.

A Bacia Hidrográfica do Rio Descoberto formou-se sobre os Grupos Paranoá (Idade Meso/Neoproterozóico) e Araxá (Idade Neoproterozóico), a maior parte da bacia pertence ao Grupo Paranoá, o Grupo Araxá está limitado ao setor sudoeste do $\mathrm{DF}^{18-20}$. Os solos que ocupam grande parte do Distrito Federal são latossolos vermelho-escuro, cambissolos e latossolos vermelho-amarelo, sendo que os latossolos ocupam mais da metade da Bacia do Descoberto ${ }^{21,22}$.

A cobertura vegetal na Bacia é do tipo campo limpo de cerrado, cerrado, vegetação herbácea (ervas) de zonas úmidas, mata ciliar e reflorestamento ${ }^{18,22}$, ocupando $33 ; 20,5 ; 13,6 ; 5$ e 1,5\% da Bacia, respectivamente.

Quanto ao clima, o DF possui duas épocas bem distintas. A época seca, que corresponde também ao período frio, compreende os meses de abril a setembro e acentuadamente junho e julho, onde o índice de precipitação pode ser nulo e as temperaturas variam entre as médias de 16 e $18{ }^{\circ} \mathrm{C}$. A época chuvosa, que corresponde ao período quente do ano com temperatura máxima de $32{ }^{\circ} \mathrm{C}$, prolonga-se de outubro a março, sendo que a maior concentração de chuva é no mês de dezembro e a precipitação média varia de 1.500 a $1.750 \mathrm{~mm}^{23}$.

\section{PARTE EXPERIMENTAL}

\section{Materiais e métodos}

Foram selecionados pontos que apresentavam possíveis ações antrópicas, identificados usando-se um GPS modelo Garmin 45XL, como mostrado na Tabela 1. Em cada ponto coletou-se uma amostra por época do ano: na época seca (outubro/1999) que corresponde aos pontos 1 a 9, e na época chuvosa (março/2000) correspondendo aos mesmos pontos. No total foram coletadas 18 amostras, como mostra a Figura 1 com a localização dos pontos.

Tabela 1. Pontos de coleta de amostras nas duas épocas do ano e suas localizações

\begin{tabular}{cc}
\hline Pontos de Coleta & $\begin{array}{c}\text { Coordenadas } \\
\text { UTM Leste/ Norte }\end{array}$ \\
\hline 1 & $813.429 / 8.246 .190$ \\
2 & $802.426 / 8.244 .827$ \\
3 & $803.550 / 8.256 .304$ \\
4 & $803.130 / 8.258 .840$ \\
5 & $796.071 / 8.264 .797$ \\
6 & $796.243 / 8.252 .926$ \\
7 & $791.730 / 8.237 .321$ \\
8 & $794.158 / 8.235 .499$ \\
9 & $791.735 / 8.225 .341$ \\
\hline
\end{tabular}

\section{Descrição dos pontos de amostragem}

Ponto 1: localizado no Córrego Taguatinga, que passa pela cidade de Taguatinga e próximo às cidades de Ceilândia, Samambaia e Águas Claras. Este ponto está assentado sobre rochas do Grupo Paranoá da unidade metarritmito arenoso. Nas proximidades deste ponto existem chácaras com culturas temporárias (hortigranjeiros), anuais (soja e milho) e permanentes (frutíferas e café). O Córrego Taguatinga possui matas ciliares em quase toda a sua extensão.

Ponto 2: localizado no Rio Melchior, próximo ao ponto 1, onde também se encontram chácaras com plantações. Neste ponto foi observada a exploração de areias, situação que segundo Falcomer ${ }^{17}$ vem aumentando nos últimos anos, ocasionando o desmatamento das matas ciliares e aumentando o processo erosivo do solo e o escoamento de resíduos de adubos e defensivos agrícolas para os mananciais próximos.

Ponto 3: localizado no Córrego Ribeirão das Pedras, que segue direção oeste onde conflui com o Lago Descoberto. É uma Área de Proteção Ambiental (APA) do Rio Descoberto e área do INCRA, com plantações de hortaliças, milho, feijão, café, etc.

Ponto 4: situado no Ribeirão Rodeador, próximo à Colônia Alexandre de Gusmão do INCRA, com plantações de hortaliças, etc.

Ponto 5: localizado no alto curso do $\mathrm{RD}$, antes da confluência com o Lago Descoberto, onde pela margem direita está o estado de Goiás tornando, assim, o próprio Rio a divisa oeste do DF, próximo à cidade de Brazlândia e aos Loteamentos Parque das Nações e Parque Colonial, que fazem parte de Goiás.

Ponto 6: localizado no RD em área de Lazer Ecológico, onde há corredeiras e quedas d'água na divisa do DF e Goiás, próximo à barragem do Lago Descoberto. A rocha predominante é do Grupo Paranoá (quartzito e metassiltito).

Ponto 7: localizado no RD, antes da foz do Rio Melchior e próximo à cidade de Santo Antônio do Descoberto/GO. É uma área sem matas ciliares.

Ponto 8: localizado no RD após a foz do Rio Melchior, divisa do DF/GO, na entrada da cidade de Santo Antônio do Descoberto. Está assentado sobre rocha do Grupo Araxá.

Ponto 9: localizado no RD, com muita mata ciliar. Apresenta rochas do tipo quartzito e micaxisto. É o ponto na saída do DF. 


\section{Amostragens}

Foram realizadas de acordo com $\mathrm{Agudo}^{24}$, utilizando-se garrafas de polietileno de aproximadamente $1000 \mathrm{~mL}$. Foram registrados in situ $\mathrm{pH}$, temperatura, condutividade elétrica (CE) e sólidos totais dissolvidos (STD).

As amostras então foram identificadas e transportadas para o laboratório.

\section{Laboratório}

A parte experimental foi realizada no Laboratório de Geoquímica do Instituto de Geociências da UnB.

De cada amostra de água retirou-se um volume de aproximadamente $500 \mathrm{~mL}$ mediante filtragem em membranas de celulose $0,45 \mu^{25}$, usando-se equipamento de vácuo marca Millipore modelo Sterifil 500, depois acidificados com $\mathrm{HNO}_{3} 2 \mathrm{~mol} \mathrm{~L}^{-1}$ até $\mathrm{pH}<$ 2 e estocados a $4{ }^{\circ} \mathrm{C}$, para determinação dos elementos $\mathrm{Mo}, \mathrm{La}, \mathrm{Al}$, $\mathrm{Ba}, \mathrm{Ca}, \mathrm{Cd}, \mathrm{Cr}, \mathrm{Cu}, \mathrm{Fe}, \mathrm{Mg}, \mathrm{Mn}, \mathrm{Ni}, \mathrm{P}, \mathrm{Si}, \mathrm{Ti}, \mathrm{V}, \mathrm{Zn}, \mathrm{Sr}, \mathrm{Zr}, \mathrm{Co}, \mathrm{Y}$, $\mathrm{Na}$ e $\mathrm{K}$. O volume restante $(\approx 500 \mathrm{~mL})$ foi submetido à determinação de $\mathrm{NO}_{3}^{-}, \mathrm{SO}_{4}^{2-}, \mathrm{PO}_{4}^{3-}, \mathrm{NH}_{4}^{+}, \mathrm{NO}_{2}^{-}, \mathrm{Cl}^{-}, \mathrm{HCO}_{3}^{-}$e dos parâmetros turbidez, cor e alcalinidade.

\section{Análises químicas}

$\mathrm{O} \mathrm{pH}$ e a temperatura foram determinados através de um medidor de $\mathrm{pH}$ marca Schoot Gerate, modelo CG818, previamente calibrado.
A CE e os STD foram determinados utilizando-se condutivímetro marca Hach, modelo 4460, também previamente calibrado.

Os parâmetros turbidez, cor, $\mathrm{NO}_{3}^{-}, \mathrm{SO}_{4}^{2-}, \mathrm{PO}_{4}^{3-}, \mathrm{NH}_{4}^{+}$e $\mathrm{NO}_{2}$ foram determinados seguindo os procedimentos do Standard Methods $^{26}$. O cloreto e a alcalinidade foram determinados pelo método titrimétrico.

$\mathrm{O}$ bicarbonato foi obtido através da fórmula $\mathrm{HCO}_{3}^{-}=$ Alcalinidade x 1,22 , segundo Sawyer ${ }^{27}$.

Os elementos $\mathrm{Mo}, \mathrm{La}, \mathrm{Al}, \mathrm{Ba}, \mathrm{Ca}, \mathrm{Cd}, \mathrm{Cr}, \mathrm{Cu}, \mathrm{Fe}, \mathrm{Mg}, \mathrm{Mn}, \mathrm{Ni}$, P, Si, Ti, V, Zn, Sr, Zr, Co e Y foram determinados utilizando-se espectrometria de emissão óptica com plasma indutivamente acoplado (ICP/OES) da marca Spectro Analytical Instrumental $\mathrm{GmbH}$, modelo Spectroflame FVM03, equipado com monocromador com rede holográfica de 2400 estrias/mm e policromadores no vácuo e no ar. Os elementos $\mathrm{Na}$ e $\mathrm{K}$ foram determinados por espectrometria de absorção atômica (EAA), marca Perkin Elmer, modelo 603 de duplo feixe.

\section{RESULTADOS E DISCUSSÃO}

\section{Parâmetros físico-químicos}

Os resultados dos parâmetros físico-químicos da água da BHRD estão apresentados na Tabela 2, juntamente com os valores permitidos pelo CONAMA ${ }^{28}$. Nesta tabela estão apresentados os valores "outliers", que são aqueles considerados acima do intervalo: média $+2 \sigma ; \sigma=$ desvio padrão, e estes se concentram principalmente no ponto 1 .

Tabela 2. Parâmetros físico-químicos da água da BHRD com os valores máximos permitidos (VMP)

\begin{tabular}{|c|c|c|c|c|c|c|c|c|c|c|c|c|c|c|}
\hline Pontos & Época & $\mathrm{pH}$ & $\begin{array}{l}\text { STD } \\
\mathrm{mg} / \mathrm{L}\end{array}$ & $\begin{array}{c}\mathrm{CE} \\
\mu \mathrm{S} / \mathrm{cm}\end{array}$ & $\stackrel{{ }^{\mathrm{T}}}{{ }^{\circ} \mathrm{C}}$ & $\begin{array}{l}\text { Cor } \\
\text { UH }\end{array}$ & $\begin{array}{l}\text { Turb. } \\
\text { UT }\end{array}$ & $\begin{array}{l}\mathrm{NO}_{3}^{-} \\
\mathrm{mg} / \mathrm{L}\end{array}$ & $\begin{array}{l}\mathrm{SO}_{4}^{2-} \\
\mathrm{mg} / \mathrm{L}\end{array}$ & $\begin{array}{l}\mathrm{PO}_{4}^{3-} \\
\mathrm{mg} / \mathrm{L}\end{array}$ & $\begin{array}{l}\mathrm{NH}_{4}^{+} \\
\mathrm{mg} / \mathrm{L}\end{array}$ & $\begin{array}{c}\mathrm{Cl}^{-} \\
\mathrm{mg} / \mathrm{L}\end{array}$ & $\begin{array}{l}\text { Alcal. } \\
\mathrm{mg} / \mathrm{L}\end{array}$ & $\begin{array}{l}\mathrm{HCO}_{3}^{-} \\
\mathrm{mg} / \mathrm{L}^{-}\end{array}$ \\
\hline 1 & $\mathrm{~s}$ & 6,5 & $189 *$ & $405^{*}$ & 25,5 & $86^{*}$ & $150 *$ & $8^{*}$ & $23^{*}$ & 8 & 38 & 43 & 121 & 148 \\
\hline 2 & s & 6,0 & 129 & 262 & 25,6 & 27 & 73 & 3 & 18 & 2 & 10 & 48 & 110 & 134 \\
\hline 3 & $\mathrm{~s}$ & 6,6 & 9 & 20,7 & 27,0 & 2 & 9 & 1 & 3 & $<\mathrm{LD}$ & $<\mathrm{LD}$ & 20 & 17 & 20 \\
\hline 4 & s & 5,2 & 4 & 9,5 & 23,0 & 2 & 9 & 1 & 3 & $<\mathrm{LD}$ & $<\mathrm{LD}$ & 13 & 6 & 8 \\
\hline 5 & $\mathrm{~s}$ & 5,2 & 3 & 6,4 & 23,0 & 3 & 6 & 1 & 3 & $<\mathrm{LD}$ & $<\mathrm{LD}$ & 13 & 3 & 3 \\
\hline 6 & s & 4,5 & 8 & 16,8 & 25,0 & 4 & 7 & 1 & 3 & $<\mathrm{LD}$ & $<\mathrm{LD}$ & 10 & 4 & 5 \\
\hline 7 & $\mathrm{~s}$ & 6,1 & 20 & 43,7 & 25,0 & 9 & 12 & 1 & 4 & $<\mathrm{LD}$ & $<\mathrm{LD}$ & 8 & 22 & 27 \\
\hline 8 & s & 6,8 & 87 & 182,5 & 25,0 & 15 & 25 & 2 & 7 & 2 & 10 & 23 & 36 & 44 \\
\hline 9 & $\mathrm{~s}$ & 6,2 & 86 & 182,7 & 25,4 & 20 & 38 & 3 & 8 & 1 & 8 & 23 & 31 & 38 \\
\hline Média & $\mathrm{s}$ & 5,9 & 59 & 125,5 & 24,9 & 19 & 37 & 2 & 8 & 3 & 17 & 22 & 39 & 47 \\
\hline Desvio padrão $(\sigma)$ & $\mathrm{s}$ & 1 & 63 & 134 & 1 & 25 & 45 & 2 & 7 & 3 & 12 & 13 & 42 & 52 \\
\hline Média+2 $\sigma$ & $\mathrm{s}$ & 7 & 186 & 392 & 27 & 69 & 127 & 7 & 22 & 9 & 41 & 49 & 124 & 151 \\
\hline$\overline{1}$ & $\mathrm{c}$ & 6,3 & 41 & 92,1 & 25,3 & $78^{*}$ & $1200 *$ & 4 & $78 *$ & 1 & 3 & $175 *$ & $90 *$ & $110^{*}$ \\
\hline 2 & $\mathrm{c}$ & 4,2 & $65^{*}$ & $136,6^{*}$ & 23,3 & 5 & 27 & 4 & 20 & 1 & $<\mathrm{LD}$ & 33 & 75 & 92 \\
\hline 3 & $\mathrm{c}$ & 6,3 & 9 & 19,1 & 22,8 & 0 & 16 & 1 & 16 & $<\mathrm{LD}$ & $<\mathrm{LD}$ & 10 & 13 & 16 \\
\hline 4 & $\mathrm{c}$ & 6,2 & 4 & 9,1 & 24 & 0 & 17 & 1 & 6 & $<\mathrm{LD}$ & $<\mathrm{LD}$ & 10 & 6 & 7 \\
\hline 5 & $\mathrm{c}$ & 5,8 & 3 & 6,6 & 25 & 2 & 7 & 1 & 4 & $<\mathrm{LD}$ & $<\mathrm{LD}$ & 15 & 3 & 4 \\
\hline 6 & $\mathrm{c}$ & 4,3 & 6 & 13,7 & $26,4 *$ & 31 & 21 & 1 & 20 & $<\mathrm{LD}$ & $<\mathrm{LD}$ & 13 & 4 & 4 \\
\hline 7 & $\mathrm{c}$ & 7,0 & 10 & 22,1 & 24,2 & 20 & 45 & 2 & 8 & $<\mathrm{LD}$ & $<\mathrm{LD}$ & 15 & 19 & 23 \\
\hline 8 & $\mathrm{c}$ & 6,9 & 23 & 47,9 & 24,5 & 19 & 42 & 2 & 34 & $<\mathrm{LD}$ & 1 & 20 & 25 & 30 \\
\hline 9 & $\mathrm{c}$ & 6,8 & 10 & 22 & 24 & 23 & 148 & 3 & 17 & $<\mathrm{LD}$ & 1 & 25 & 24 & 29 \\
\hline Média & $\mathrm{c}$ & 6,0 & 19 & 41,0 & 24,4 & 20 & 169 & 2 & 23 & 1 & 2 & 35 & 29 & 35 \\
\hline Desvio padrão $(\sigma)$ & $\mathrm{c}$ & 1 & 20 & 42 & 1 & 23 & 367 & 1 & 21 & 0 & 1 & 50 & 30 & 37 \\
\hline Média+2 $\sigma$ & $\mathrm{c}$ & 8 & 59 & 125 & 26 & 66 & 902 & 5 & 65 & 1 & 4 & 135 & 89 & 108 \\
\hline VMP/Portaria 1469 & & $6,5-8,5$ & 1000 & - & - & 15 & 5 & 10 & 250 & - & 1,5 & 250 & - & - \\
\hline CONAMA Classe 2 & & $6-9$ & 10 & - & - & 75 & 100 & 10 & 250 & 0,025 & 0,02 & 250 & - & - \\
\hline
\end{tabular}

$\mathrm{s}=$ seca; $\mathrm{c}=$ chuva; * valores "outliers"; $<\mathrm{LD}=$ menor que o limite de detecção; UH= Unidade Hasen (mg Pt-Co/L); UT= Unidade de Turbidez; Portaria ${ }^{\circ} 1469^{33}$; CONAMA $^{28}$. 
$\mathrm{O} \mathrm{pH}$ variou de 4,2 a 7,0, ficando com média 5,9 na época seca e 6,0 na chuvosa, estando dentro da média dos rios do DF (5,6 a 6,85), Tabela 3.

A turbidez apresentou média de 37 e 169 uT nas épocas seca e chuvosa, respectivamente, com tendência a aumentar na época chuvosa. Este comportamento mostra os efeitos do transporte de material sólido para os leitos dos rios.

A alta concentração média de turbidez na época chuvosa foi devida ao valor "outlier" de $1200 \mathrm{uT}$, registrado no ponto 1 na época chuvosa, que também possui valores "outliers" de cor, $\mathrm{SO}_{4}^{2-} \mathrm{e}$ $\mathrm{Cl}^{-}$, evidenciando a possível influência de esgoto doméstico.

A cor oscilou de 2 a 86 UH na época seca e de 0 a 78 UH na chuvosa. Em alguns pontos $(6,7,8$ e 9) tendeu a aumentar na época chuvosa. O ponto 6 possui corredeiras e quedas d'água que podem proporcionar esse aumento da turbidez na época chuvosa, através do aumento de material em suspensão; os pontos 8 e 9, por receberem rejeitos domésticos "diluídos" do Rio Melchior.

O ponto 1 (épocas seca e chuvosa), com relação à cor, é o único que ultrapassou o limite estabelecido pelo CONAMA (Tabela 2).

A média de STD foi de 59 na época seca e $19 \mathrm{mg} \mathrm{L}^{-1}$ na chuvosa e a CE foi de 125 na seca e $41 \mu \mathrm{S} \mathrm{cm}^{-1}$ na chuvosa. Ambos os parâmetros, STD e CE, tendem a diminuir suas concentrações na época chuvosa em todos os pontos. Os valores "outliers" desses parâmetros referem-se ao ponto 1 na época seca e ao ponto 2 na época chuvosa. Entretanto, os valores de STD não ultrapassaram o estabelecido pelo CONAMA (Tabela 2).

Comparando-se com outras bacias hidrográficas dentro do DF (Tabela 3), nota-se que as médias de STD e CE na BHRD, principalmente na época seca, ficaram acima das médias e aproximamse das medidas das regiões de Mestre D’Armas e Sobradinho. Estas últimas são regiões com bastante influência urbana.

A alcalinidade apresentou valores entre 3 e 121 na época seca e 3 a $90 \mathrm{mg} \mathrm{L}^{-1}$ na chuvosa e o $\mathrm{HCO}_{3}^{-}$, de 3 a 148 na seca e 4 a 110 $\mathrm{mg} \mathrm{L}^{-1}$ na chuvosa.
$\mathrm{O}$ nitrito $\left(\mathrm{NO}_{2}^{-}\right)$foi determinado, mas não foi detectado em nenhum ponto, mesmo porque a oxidação do $\mathrm{NO}_{2}^{-}$em $\mathrm{NO}_{3}^{-}$é bastante rápida, em função das condições oxidantes do meio.

A média de $\mathrm{NO}_{3}^{-}$nas épocas seca e chuvosa foi $2 \mathrm{mg} \mathrm{L}^{-1}$. Para o $\mathrm{NH}_{4}^{+}$a média foi de 17 na época seca e $2 \mathrm{mg} \mathrm{L}^{-1}$ na chuvosa. Isso demonstra que na época seca a concentração de $\mathrm{NH}_{4}^{+}$é maior que a de $\mathrm{NO}_{3}^{-}$.

Os teores de $\mathrm{NO}_{3}^{-}$na BHRD não ultrapassaram o limite do CONAMA e nem da Portaria ${ }^{\circ} 1469$ (Tabela 2).

Os parâmetros $\mathrm{NO}_{3}^{-}$e $\mathrm{NH}_{4}^{+}$ficaram acima da média de outras regiões dentro do DF (Tabela 3). O ponto que apresenta valores altos para esses parâmetros é o ponto 1 (época seca), reforçando os valores encontrados na literatura.

Poluentes com altas concentrações de $\mathrm{NO}_{3}^{-}$ao atingirem as águas dos rios têm seus teores diluídos, podendo chegar a concentrações infinitesimais. Vale ressaltar que após um determinado tempo, tais teores começam a aumentar e, em seguida, inicia-se uma regressão às condições similares àquelas ao montante do lançamento, processo este observado durante a realização deste trabalho. No ponto 1 (Córrego Taguatinga), época seca, detectou-se 8 mg L ${ }^{-1}$ de $\mathrm{NO}_{3}^{-}$, diminuindo para $3 \mathrm{mg} \mathrm{L}^{-1}$ no ponto 2 (Rio Melchior) e, de acordo com a própria diluição do rio, atingindo teor de $2 \mathrm{mg}$ $\mathrm{L}^{-1}$, no ponto 8 (Rio Descoberto). Entretanto, no ponto 9 a concentração aumenta novamente, ficando similar ao ponto 2. Assim, no encontro do Rio Descoberto com o Rio Corumbá a concentração pode estar similar à do ponto 1 .

$\mathrm{O}$ sulfato e o cloreto encontram-se em maiores concentrações na época chuvosa; o $\mathrm{SO}_{4}^{2-}$ com média de 8,0 na época seca e $23 \mathrm{mg}$ $\mathrm{L}^{-1}$ na chuvosa; o $\mathrm{Cl}^{-}$com 22 na época seca e $35 \mathrm{mg} \mathrm{L}^{-1}$ na chuvosa (Tabela 2).

Os valores de $\mathrm{SO}_{4}^{2-}$ e $\mathrm{Cl}^{-}$não ultrapassaram os limites do CONAMA. Porém, esses parâmetros ultrapassam a média nacio-

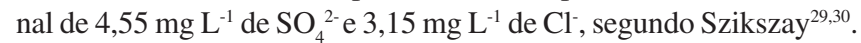
As possíveis fontes de $\mathrm{Cl}^{-}$são os esgotos domésticos e/ou fertilizantes.

Tabela 3. Valores médios dos parâmetros físico-químicos (mg/L), elementos-traço e maiores ( $\mu \mathrm{g} \mathrm{L}^{-1}$ ) em diferentes mananciais do DF. (a) Região Hidrográfica Ribeirão do Gama4; (b) Região Hidrográfica Mestre D’ $\operatorname{Armas}^{3,5}$; (c) Região Hidrográfica Bananal²; (d) Região Hidrográfica do Lago Descoberto ${ }^{3,5}$; (e) Região Hidrográfica Sobradinho ${ }^{3,5}$; (f) Região Hidrográfica Pipiripau ${ }^{3,5}$ e (g) Região Hidrográfica Lago Paranoá ${ }^{3,5}$

\begin{tabular}{|c|c|c|c|c|c|c|c|c|c|}
\hline & \multirow[t]{2}{*}{ (a) } & \multirow[t]{2}{*}{ (b) } & \multirow[t]{2}{*}{ (c) } & \multirow[t]{2}{*}{ (d) } & \multirow[t]{2}{*}{ (e) } & \multirow[t]{2}{*}{ (f) } & \multirow[t]{2}{*}{ (g) } & \multicolumn{2}{|c|}{ BHRD (média) } \\
\hline & & & & & & & & Seca & Chuvosa \\
\hline $\mathrm{pH}$ & 6,85 & 6,00 & 5,60 & 5,67 & 6,00 & 6,00 & 5,86 & 5,9 & 6,0 \\
\hline $\mathrm{T}^{\circ} \mathrm{C}$ & 19,56 & 24,07 & 23,98 & 21,76 & 17,50 & 17,35 & 22,31 & 24,9 & 24,4 \\
\hline $\mathrm{CE}(\mu \mathrm{S} / \mathrm{cm})$ & 9,08 & 109,30 & 36,00 & 12,60 & 105,70 & 20,05 & 18,46 & 125,5 & 41,0 \\
\hline \multicolumn{10}{|l|}{$\mathrm{mg} \mathrm{L}^{-1}$} \\
\hline Alcalinidade & 0,83 & 0,97 & 1,86 & 1,51 & 7,97 & 2,80 & 8,37 & 39,0 & 29,0 \\
\hline $\mathrm{NO}_{3}^{-}$ & 0,12 & 0,15 & 0,06 & 0,27 & 1,47 & 0,15 & 0,21 & 2,0 & 2,0 \\
\hline $\mathrm{PO}_{4}^{3-}$ & 0,12 & 0,52 & 0,62 & 0,13 & 0,19 & 0,12 & 0,70 & 3,0 & 1,0 \\
\hline $\mathrm{NH}_{4}^{+}$ & 0,16 & 0,16 & 0,02 & 0,35 & 1,29 & 0,11 & 0,16 & 17,0 & 2,0 \\
\hline STD & 4,16 & 54,90 & 23,12 & 6,24 & 52,93 & 9,90 & 9,14 & 59,0 & 19,0 \\
\hline \multicolumn{10}{|l|}{$\mathrm{mg} \mathrm{L}^{-1}$} \\
\hline $\mathrm{Ca}$ & 21800 & 2620 & 4880 & 1070 & 1810 & 4200 & 1550 & 5370 & 1410 \\
\hline $\mathrm{Mg}$ & 120 & 1240 & 470 & 170 & 780 & 1520 & 0480 & 1760 & 800 \\
\hline $\mathrm{Fe}$ & 120 & 80 & 340 & 350 & 210 & 420 & 1440 & 340 & 150 \\
\hline $\mathrm{Si}$ & 1910 & 2430 & 3080 & 3320 & 1850 & 2140 & 3920 & 3380 & 2580 \\
\hline $\mathrm{Ni}$ & 10 & 40 & 50 & 30 & 20 & 40 & 70 & 40 & 60 \\
\hline $\mathrm{Al}$ & 50 & 100 & 170 & 1020 & 50 & 80 & 100 & 80 & 110 \\
\hline $\mathrm{P}$ & 10 & 480 & 350 & 620 & 250 & 1010 & 400 & 210 & 50 \\
\hline $\mathrm{K}$ & 250 & 630 & 590 & 560 & 10 & 1180 & 1130 & 4090 & 1300 \\
\hline $\mathrm{Na}$ & 280 & 1620 & 620 & 2100 & 10 & 1650 & 540 & 17980 & 2840 \\
\hline
\end{tabular}


Os valores "outliers" de $\mathrm{SO}_{4}^{2-}$ e $\mathrm{Cl}^{-}$correspondem ao ponto 1 . No caso do $\mathrm{SO}_{4}^{2-}$, os resultados anômalos estão associados ao intemperismo e ao transporte de materiais para o leito do rio.

O fosfato foi detectado apenas nos pontos 1,2,8 e 9, na época seca, e nos pontos 1 e 2 na chuvosa, e apresentou concentrações acima do estabelecido pelo CONAMA, estando também acima das concentrações médias dentro do DF (Tabela 3).

$\mathrm{Na}$ maioria dos pontos o $\mathrm{PO}_{4}^{3-}$ não foi detectado. Assim, sugerese que o $\mathrm{PO}_{4}^{3-}$ pode ter sido adsorvido pelas argilas, visto que esta é a forma mais importante de acesso desta espécie química no ambiente aquático ${ }^{31}$. As possíveis fontes de $\mathrm{PO}_{4}^{3-}$ na área de estudo são, principalmente, esgoto doméstico e fertilizantes agrícolas.

\section{Elementos-traço e maiores}

Os elementos podem ser liberados de forma parcial ou total a partir dos sedimentos devido às modificações dos parâmetros físico-químicos, principalmente $\mathrm{pH}$ e temperatura do corpo hídrico.

As Tabelas 4 e 5 mostram os resultados dos elementos maiores e traços, respectivamente, nas águas da BHRD (expressos em $\mu \mathrm{g} \mathrm{L}^{-1}$ ) em cada estação climática. Foram destacados os valores "outliers" considerados fora do intervalo (média $+2 \sigma$ ) e retirados os elementos $\mathrm{La}, \mathrm{Cd}, \mathrm{Y}, \mathrm{Ti}, \mathrm{Ni}, \mathrm{Zr}, \mathrm{Cu}$ e Co por apresentarem valores abaixo do limite de detecção (<L.D) ou concentrações muito baixas.

Os elementos La, Y e Zr estão associados aos normalizadores geoquímicos e à ausência de situações antrópicas ligadas a eles, ou seja, são elementos tipicamente de origem geológica.
Os elementos presentes na água em concentrações significativas são $\mathrm{Ca}, \mathrm{Mg}, \mathrm{Fe}, \mathrm{Si}, \mathrm{P}, \mathrm{Na}$ e $\mathrm{K}$.

$\mathrm{O}$ ferro apresentou valores que ultrapassavam o estabelecido pelo CONAMA, como nos pontos 1, 2, 6, 7 e 8 na época seca. Entretanto, os teores de Fe são compatíveis com os encontrados na região, em função de aspectos geológicos regionais (Tabela 3).

O cálcio está predominantemente associado aos íons carbonato e bicarbonato. Pode ser precipitado ou dissolvido com a variação do $\mathrm{pH}$.

Os elementos $\mathrm{La}, \mathrm{Cd}, \mathrm{Y}, \mathrm{Zr}, \mathrm{Cu}$ e Co apresentaram valores baixos ou abaixo dos limites de detecção $(<\mathrm{L}$.D), principalmente na época chuvosa devido à própria diluição; portanto, são descartados no tratamento estatístico. Os teores baixos podem indicar a adsorção desses elementos nas partículas finas dos sedimentos. Entretanto, as concentrações desses elementos ultrapassam as médias dos rios do mundo (Tabela 6).

Desta forma, torna-se explícito neste estudo que os elementos $\mathrm{La}, \mathrm{Cd}, \mathrm{Y}, \mathrm{Zr}, \mathrm{Cu}$ e Co não apresentam contribuição para geoquímica local.

Manganê e bário possuem valores "outliers" no ponto 7, época seca, (Tabela 5), visto que o Mn está acima do valor estabelecido pelo CONAMA.

As concentrações de $\mathrm{Na}$ e K estão acima da média de sistemas fluviais dentro do DF (Tabela 3), enquanto que para o Brasil e o mundo (Tabela 6) somente a média de $\mathrm{K}$ na época chuvosa se aproximou da média dos rios da Bacia do Paraná, da América do Norte e da África. Na época chuvosa, a média de Na também se aproximou

Tabela 4. Concentrações dos elementos maiores $\left(\mu \mathrm{g} \mathrm{L}^{-1}\right)$ nas águas da BHRD

\begin{tabular}{|c|c|c|c|c|c|c|c|c|c|}
\hline Pontos & $\mathrm{Ti}$ & $\mathrm{Ca}$ & $\mathrm{Mg}$ & $\mathrm{Fe}$ & $\mathrm{Si}$ & $\mathrm{Al}$ & $\mathrm{P}$ & $\mathrm{Na}$ & $\mathrm{K}$ \\
\hline $1 \mathrm{~s}$ & 10 & 10,7 & 2470 & 510 & 3140 & 60 & $2770 *$ & 46700 & 11300 \\
\hline $2 \mathrm{~s}$ & 10 & 10900 & 2410 & 750 & 3590 & 60 & 480 & 47500 & 10200 \\
\hline $3 \mathrm{~s}$ & 10 & 1910 & 530 & 160 & 2820 & 80 & 30 & 2820 & 1020 \\
\hline $4 \mathrm{~s}$ & 10 & 570 & 450 & 110 & 2870 & 60 & 80 & 1800 & 1050 \\
\hline $5 s$ & 10 & 270 & 280 & 80 & 2850 & 40 & 50 & 1600 & 780 \\
\hline $6 s$ & 10 & 1490 & 520 & 450 & 2550 & 80 & 30 & 2440 & 1210 \\
\hline $7 \mathrm{~s}$ & 10 & 4490 & 3130 & 370 & 4140 & 130 & 60 & 2090 & 1650 \\
\hline $8 \mathrm{~s}$ & $20 *$ & 9850 & 2880 & 400 & 4360 & $240 *$ & 630 & 31400 & 4820 \\
\hline $9 \mathrm{~s}$ & 10 & 8120 & 3190 & 230 & 4090 & 110 & 340 & 25500 & 4770 \\
\hline Média & 11 & 4179 & 1762 & 340 & 3379 & 96 & 497 & 17983 & 4089 \\
\hline Desvio padrão $(\sigma)$ & 3 & 4096 & 1205 & 205 & 640 & 57 & 831 & 18817 & 3861 \\
\hline Média+2 $\sigma$ & 17 & 12372 & 4171 & 750 & 4659 & 210 & 2158 & 55618 & 11811 \\
\hline $1 \mathrm{c}$ & 40 & 9950 & 1280 & 240 & 2030 & $870 *$ & 90 & 6300 & 3130 \\
\hline $2 c$ & $<$ L.D & 8720 & 1770 & 180 & 3100 & 70 & $190 *$ & $29800^{*}$ & 3660 \\
\hline $3 c$ & $<$ L.D & 1670 & 400 & 150 & 2450 & $<$ L.D & 50 & 2680 & 840 \\
\hline $4 c$ & $<$ L.D & 400 & 300 & 80 & 2260 & $<$ L.D & 30 & 1820 & 810 \\
\hline $5 c$ & $<$ L.D & 260 & 270 & 100 & 2050 & 40 & 20 & 1610 & 860 \\
\hline $6 c$ & 20 & 1090 & 410 & $350 *$ & 2560 & 70 & 40 & 2200 & 1130 \\
\hline $7 \mathrm{c}$ & 10 & 1710 & 1260 & 220 & 2880 & 310 & 20 & 2120 & 1260 \\
\hline $8 \mathrm{c}$ & $<$ L.D & 3350 & 1460 & 150 & 3020 & 130 & 20 & 4480 & 1870 \\
\hline $9 \mathrm{c}$ & $<$ L.D & 3070 & 1470 & 120 & 3040 & 110 & 30 & 4210 & 1810 \\
\hline Média & 23 & 3358 & 958 & 177 & 2599 & 229 & 54 & 6136 & 1708 \\
\hline Desvio padrão $(\sigma)$ & 12 & 3356 & 566 & 79 & 404 & 275 & 52 & 8493 & 982 \\
\hline Média+2 $\sigma$ & 48 & 10069 & 2090 & 334 & 3406 & 778 & 159 & 23121 & 3672 \\
\hline $\begin{array}{l}\text { Portaria } n^{\circ} 1469 \\
{[\mathrm{mg} / \mathrm{L}]}\end{array}$ & - & {$[200]$} & {$[150]$} & 300 & - & 200 & - & [200] & - \\
\hline CONAMA & - & - & - & 300 & - & 100 & - & - & - \\
\hline
\end{tabular}

$<$ L.D = abaixo do Limite de Detecção; s = época seca; c = época chuvosa; *valores "outliers" 
Tabela 5. Concentrações dos elementos-traço $\left(\mu \mathrm{g} \mathrm{L}^{-1}\right)$ nas águas da BHRD

\begin{tabular}{|c|c|c|c|c|c|c|c|c|}
\hline Pontos & $\mathrm{Sr}$ & Mo & V & $\mathrm{Zr}$ & $\mathrm{Cr}$ & $\mathrm{Mn}$ & $\mathrm{Ba}$ & $\mathrm{Zn}$ \\
\hline $1 \mathrm{~s}$ & 110 & 30 & 10 & 10 & 10 & 20 & 10 & 20 \\
\hline $2 \mathrm{~s}$ & 170 & 70 & 10 & 10 & 20 & 140 & 20 & 30 \\
\hline $3 \mathrm{~s}$ & 170 & 80 & 20 & 10 & 20 & 10 & 20 & 20 \\
\hline $4 s$ & 130 & 80 & 20 & 10 & 10 & 10 & 20 & 20 \\
\hline $5 \mathrm{~s}$ & 100 & 40 & 10 & 10 & 10 & 10 & 20 & 10 \\
\hline $6 \mathrm{~s}$ & 110 & 70 & 10 & 10 & 10 & 20 & 10 & 10 \\
\hline $7 \mathrm{~s}$ & 240 & 140 & 30 & 20 & 20 & $800 *$ & $300 *$ & 20 \\
\hline $8 \mathrm{~s}$ & $410 *$ & $190 *$ & $40 *$ & $30 *$ & $40 *$ & 60 & 40 & 20 \\
\hline $9 \mathrm{~s}$ & 90 & 40 & 10 & 10 & 10 & 30 & 20 & 10 \\
\hline Média & 170 & 82 & 18 & 13 & 17 & 122 & 51 & 18 \\
\hline Desvio padrão $(\sigma)$ & 96 & 49 & 10 & 7 & 9 & 243 & 88 & 6 \\
\hline Média+2 $\sigma$ & 362 & 180 & 38 & 27 & 36 & 608 & 228 & 30 \\
\hline $1 \mathrm{c}$ & 140 & 60 & 10 & 10 & 10 & 10 & 30 & 20 \\
\hline $2 \mathrm{c}$ & 130 & 50 & 10 & 10 & 10 & 50 & 30 & 20 \\
\hline $3 \mathrm{c}$ & 80 & 40 & 10 & 10 & 10 & 10 & 20 & 20 \\
\hline $4 \mathrm{c}$ & 70 & 40 & 10 & 10 & 10 & 10 & 20 & 30 \\
\hline $5 c$ & 70 & 40 & 10 & 10 & 10 & $<$ L.D & $70 *$ & $110 *$ \\
\hline $6 \mathrm{c}$ & 80 & 40 & 10 & 10 & 10 & $<$ L.D & 10 & 10 \\
\hline $7 \mathrm{c}$ & 90 & 50 & 10 & 10 & 10 & 30 & 40 & 10 \\
\hline $8 \mathrm{c}$ & 90 & 50 & 10 & 10 & 10 & 30 & 50 & 20 \\
\hline $9 \mathrm{c}$ & 90 & 60 & 10 & 10 & 10 & 30 & 20 & 10 \\
\hline Média & 93 & 48 & 10 & 10 & 10 & 24 & 32 & 28 \\
\hline Desvio padrão $(\sigma)$ & 24 & 8 & 0 & 0 & 0 & 14 & 17 & 30 \\
\hline Média+2 $\sigma$ & 140 & 63 & 10 & 10 & 10 & 52 & 67 & 87 \\
\hline Portaria $\mathrm{n}^{\circ} 1469[\mathrm{mg} / \mathrm{L}]$ & - & - & - & - & 50 & 100 & 700 & 5000 \\
\hline CONAMA & - & - & 100 & - & 50 & 100 & 1000 & 180 \\
\hline
\end{tabular}

$<$ L.D = abaixo do Limite de Detecção; s= época seca; c= época chuvosa; *valores "outliers"

Tabela 6. Concentração média dos elementos-traço e maiores $\left(\mu \mathrm{g} \mathrm{L}^{-1}\right)$ em águas no Brasil e no mundo: (a) rios da América do Norte $^{29,34}$; (b) média de rios do Mundo ${ }^{29}$; (c) rio Tietê-SP/Brasil ${ }^{32} \mathrm{e}$ (d) média dos rios da Bacia do Paraná/Brasil ${ }^{33}$

\begin{tabular}{|c|c|c|c|}
\hline (a) (b) & (c) & (d) & $\begin{array}{c}\text { BHRD } \\
\text { Seca Chuvosa }\end{array}$ \\
\hline
\end{tabular}

\begin{tabular}{ccccccc}
\hline Elementos & \multicolumn{5}{c}{$\mu \mathrm{g} \mathrm{L}^{-1}$} \\
$\mathrm{Fe}$ & 300 & 40 & 150 & 720 & 340 & 150 \\
$\mathrm{Zn}$ & 0 & 15 & na & na & 20 & 10 \\
$\mathrm{Mn}$ & 20 & 4 & 10 & 10 & 40 & 20 \\
$\mathrm{Mo}$ & 0 & 0,5 & na & na & 70 & 50 \\
$\mathrm{Ni}$ & 10 & 0,3 & 0 & 10 & 40 & 60 \\
$\mathrm{Si}$ & 4100 & 6000 & 3100 & 3360 & 3380 & 2580 \\
$\mathrm{Al}$ & 240 & 300 & 10 & 860 & 80 & 110 \\
$\mathrm{Ba}$ & 50 & 20 & na & na & 20 & 30 \\
$\mathrm{Sr}$ & 60 & 70 & na & na & 140 & 80 \\
$\mathrm{Ti}$ & 10 & 3 & 10 & 40 & 10 & 0 \\
$\mathrm{Mg}$ & 5000 & 4100 & 2800 & 3400 & 1760 & 800 \\
$\mathrm{Na}$ & 9000 & 6100 & 2900 & 2000 & 17980 & 2840 \\
$\mathrm{~K}$ & 1400 & 2300 & 2700 & 1400 & 4090 & 1300 \\
$\mathrm{Ca}$ & 21000 & 18000 & 3000 & 3400 & 5370 & 1410 \\
$\mathrm{Cr}$ & na & 0,7 & na & na & 20 & 10 \\
$\mathrm{La}$ & na & 0,03 & na & na & 20 & 10 \\
$\mathrm{~V}$ & na & 0,9 & na & na & 20 & 10 \\
$\mathrm{Cu}$ & na & 3 & na & na & 10 & 0 \\
$\mathrm{Co}$ & na & 0,2 & na & na & 20 & 10 \\
\hline
\end{tabular}

na= não analisado apenas das médias dos rios da Bacia do Paraná e do rio Tietê.

A concentração do K é menor que a do Na nas águas do Rio Descoberto, ao contrário nos sedimentos de corrente, ratificando a maior afinidade do $\mathrm{K}$ para ser adsorvido pelas partículas argilosas presentes nos sedimentos. O K é um elemento bastante representativo, devido à sua participação intensa em processos de troca-iônica.

A grande concentração de $\mathrm{K}$ em águas de superfície é devida à lixiviação de fertilizantes, principalmente em áreas agrícolas ${ }^{32}$.

Entre os elementos-traço analisados, o Sr é o único que possui concentrações significativas em todos os pontos (Tabela 5), ficando acima da média de outros rios no Brasil e no mundo (Tabela 6). Além disso, sua concentração média na época chuvosa está um pouco acima da média dos rios mundiais.

\section{Correlações}

Realizou-se tratamento estatístico não paramétrico através da correlação de Spearman (R) entre parâmetros físico-químicos e elementos químicos na água da BHRD, como mostram as Tabelas 6 e 7 nas épocas seca e chuvosa, respectivamente.

Fosfato e amônio não foram detectados na maioria das amostras avaliadas durante o período chuvoso. Assim, foram excluídos do tratamento estatístico, nesta época.

$\mathrm{O}$ pH não apresentou correlação com nenhum elemento ou demais parâmetros, na época seca, porém na época chuvosa se correlacionou apenas com os elementos $\mathrm{Al}$ e $\mathrm{Ca}$, e a condutividade. Isso mostra que a grande quantidade dos elementos ocorre mais na forma solúvel em água ácida que em água neutra. 
Tabela 7. Matriz de correlação de Spearman (R) entre parâmetros físico-químicos, elementos-traço e maiores na água da BHRD, na época seca. Apenas as correlações com significância $\mathrm{p}<0,05$ são apresentadas

\begin{tabular}{|c|c|c|c|c|c|c|c|c|c|c|c|c|c|c|c|c|c|c|c|c|c|c|c|c|c|}
\hline & $\mathrm{Sr}$ & Mo & $\mathrm{Ti}$ & $\mathrm{Ca}$ & $\mathrm{Mg}$ & $\mathrm{Fe}$ & $\mathrm{Si}$ & $\mathrm{Ni}$ & $\mathrm{Al}$ & $\mathrm{Mn}$ & $\mathrm{Ba}$ & $\mathrm{P}$ & $\mathrm{Na}$ & $\mathrm{K}$ & $\mathrm{NO}_{3}^{-}$ & $\mathrm{SO}_{4}^{2-}$ & $\mathrm{PO}_{4}{ }^{3-}$ & $\mathrm{HCO}_{3}^{-}$ & $\mathrm{NH}_{4}^{+}$ & $\mathrm{Cl}^{-}$ & Alcal. & $\mathrm{pH}$ & STD & $\mathrm{CE}$ & $\mathrm{T}^{\circ} \mathrm{C}$ \\
\hline $\mathrm{Sr}$ & 1 & & & & & & & & & & & & & & & & & & & & & & & & \\
\hline Mo & 0,83 & 1 & & & & & & & & & & & & & & & & & & & & & & & \\
\hline $\mathrm{Ti}$ & 0,96 & 0,78 & 1 & & & & & & & & & & & & & & & & & & & & & & \\
\hline $\mathrm{Ca}$ & - & - & - & 1 & & & & & & & & & & & & & & & & & & & & & \\
\hline $\mathrm{Mg}$ & - & - & - & 0,68 & 1 & & & & & & & & & & & & & & & & & & & & \\
\hline $\mathrm{Fe}$ & - & - & - & 0,82 & - & 1 & & & & & & & & & & & & & & & & & & & \\
\hline $\mathrm{Si}$ & - & - & - & - & 0,78 & - & 1 & & & & & & & & & & & & & & & & & & \\
\hline $\mathrm{Ni}$ & - & - & - & - & 0,77 & - & 1,00 & 1 & & & & & & & & & & & & & & & & & \\
\hline $\mathrm{Al}$ & - & - & - & - & 0,79 & - & - & 0,70 & 1 & & & & & & & & & & & & & & & & \\
\hline $\mathrm{Mn}$ & - & - & - & 0,81 & 0,74 & 0,79 & - & - & - & 1 & & & & & & & & & & & & & & & \\
\hline $\mathrm{Ba}$ & - & - & - & - & - & - & - & 0,70 & - & - & 1 & & & & & & & & & & & & & & \\
\hline $\mathrm{P}$ & - & - & - & - & - & - & 0,81 & 0,71 & - & - & - & 1 & & & & & & & & & & & & & \\
\hline $\mathrm{Na}$ & - & - & - & 0,95 & - & 0,82 & - & - & - & 0,81 & - & - & 1 & & & & & & & & & & & & \\
\hline $\mathrm{K}$ & - & - & - & 0,93 & - & 0,85 & - & - & - & 0,74 & - & 0,81 & 0,87 & 1 & & & & & & & & & & & \\
\hline $\mathrm{NO}_{3}^{-}$ & - & - & - & 0,82 & - & - & - & - & - & 0,84 & - & 0,78 & 0,82 & 0,82 & 1 & & & & & & & & & & \\
\hline $\mathrm{SO}_{4}^{2-}$ & - & - & - & 0,91 & 0,76 & - & 0,71 & - & - & 0,87 & - & 0,80 & 0,79 & 0,91 & 0,92 & 1 & & & & & & & & & \\
\hline $\mathrm{PO}_{4}^{3-}$ & - & - & - & 0,77 & - & - & - & - & - & - & - & 0,85 & 0,77 & 0,80 & 0,90 & 0,81 & 1 & & & & & & & & \\
\hline $\mathrm{HCO}_{3}^{-}$ & - & - & - & 0,97 & 0,68 & 0,72 & - & - & - & - & - & 0,76 & 0,90 & 0,93 & 0,82 & 0,91 & 0,80 & 1 & & & & & & & \\
\hline $\mathrm{NH}_{4}^{+}$ & - & - & - & 0,88 & - & 0,69 & - & - & - & - & - & 0,87 & 0,88 & 0,91 & 0,93 & 0,88 & 0,91 & 0,91 & 1 & & & & & & \\
\hline $\mathrm{Cl}^{-}$ & - & - & - & 0,77 & - & - & - & - & - & - & - & - & 0,86 & 0,68 & 0,86 & - & 0,76 & 0,78 & 0,87 & 1 & & & & & \\
\hline Alcal. & - & - & - & 0,97 & 0,68 & 0,72 & - & - & - & - & - & 0,76 & 0,90 & 0,93 & 0,82 & 0,91 & 0,80 & 1,00 & 0,91 & 0,78 & 1 & & & & \\
\hline $\mathrm{pH}$ & - & - & - & - & - & - & - & - & - & - & - & - & - & - & - & - & - & - & - & - & - & 1 & & & \\
\hline STD & - & - & - & 1 & 0,79 & 0,74 & - & - & - & 0,96 & 0,79 & - & 0,93 & 0,93 & 0,82 & 0,91 & 0,79 & 0,98 & 0,87 & - & 0,98 & - & 1 & & \\
\hline $\mathrm{CE}$ & - & - & - & 0,98 & 0,83 & - & - & - & - & 0,93 & - & - & 0,90 & 0,90 & 0,87 & 0,94 & 0,76 & 0,95 & 0,82 & - & 0,95 & - & 0,98 & 1 & \\
\hline $\mathrm{T}^{\circ} \mathrm{C}$ & - & - & - & 0,67 & - & - & - & - & - & - & - & - & - & - & - & - & - & - & - & - & - & - & - & - & 1 \\
\hline
\end{tabular}

- abaixo do nível de significância

Tabela 8. Matriz de correlação de Spearman (R) entre parâmetros físico-químicos, elementos-traço e maiores na água da BHRD, na época chuvosa. Apenas as correlações com significância $\mathrm{p}<0,05$ são apresentadas

\begin{tabular}{|c|c|c|c|c|c|c|c|c|c|c|c|c|c|c|c|c|c|c|c|c|c|c|}
\hline & $\mathrm{Sr}$ & Mo & $\mathrm{Ti}$ & $\mathrm{Ca}$ & $\mathrm{Mg}$ & $\mathrm{Fe}$ & $\mathrm{Si}$ & $\mathrm{Al}$ & $\mathrm{Mn}$ & $\mathrm{Ba}$ & $\mathrm{P}$ & $\mathrm{Na}$ & K & $\mathrm{NO}_{3}^{-}$ & $\mathrm{SO}_{4}{ }^{2-}$ & $\mathrm{HCO}_{3}^{-}$ & $\mathrm{Cl}^{-}$ & Alcal. & $\mathrm{pH}$ & STD & $\mathrm{CE}$ & $\mathrm{T}^{\circ} \mathrm{C}$ \\
\hline $\mathrm{Sr}$ & 1 & & & & & & & & & & & & & & & & & & & & & \\
\hline Mo & 0,83 & 1,00 & & & & & & & & & & & & & & & & & & & & \\
\hline $\mathrm{Ti}$ & - & - & 1,00 & & & & & & & & & & & & & & & & & & & \\
\hline $\mathrm{Ca}$ & 0,89 & 0,79 & - & 1,00 & & & & & & & & & & & & & & & & & & \\
\hline $\mathrm{Mg}$ & 0,98 & 0,77 & - & 0,93 & 1,00 & & & & & & & & & & & & & & & & & \\
\hline $\mathrm{Fe}$ & - & - & - & - & - & 1,00 & & & & & & & & & & & & & & & & \\
\hline $\mathrm{Si}$ & 0,98 & - & - & 0,93 & 0,75 & - & 1,00 & & & & & & & & & & & & & & & \\
\hline $\mathrm{Al}$ & - & - & - & - & - & - & - & 1,00 & & & & & & & & & & & & & & \\
\hline $\mathrm{Mn}$ & 0,76 & - & - & 0,86 & 0,85 & - & 0,72 & - & 1,00 & & & & & & & & & & & & & \\
\hline $\mathrm{Ba}$ & - & - & - & - & - & - & - & - & - & 1,00 & & & & & & & & & & & & \\
\hline $\mathrm{P}$ & - & - & - & - & - & - & - & - & - & - & 1,00 & & & & & & & & & & & \\
\hline $\mathrm{Na}$ & 0,79 & 0,71 & - & 0,89 & 0,81 & - & - & - & - & - & - & 1,00 & & & & & & & & & & \\
\hline $\mathrm{K}$ & 0,93 & 0,93 & - & 0,82 & 0,83 & - & - & - & - & - & - & 0,79 & 1,00 & & & & & & & & & \\
\hline $\mathrm{NO}_{3}^{-}$ & 0,93 & 0,79 & - & 0,84 & 0,87 & - & - & - & 0,76 & - & - & 0,74 & 0,89 & 1,00 & & & & & & & & \\
\hline $\mathrm{SO}_{4}^{2-}$ & 0,72 & - & - & 0,75 & 0,74 & - & 0,74 & - & - & - & - & 0,89 & - & - & 1,00 & & & & & & & \\
\hline $\mathrm{HCO}_{3}^{-}$ & 0,84 & - & - & 0,94 & 0,87 & - & 0,87 & - & 0,95 & - & - & 0,77 & - & 0,90 & - & 1,00 & & & & & & \\
\hline $\mathrm{Cl}^{-}$ & 0,88 & 0,80 & - & - & 0,81 & - & 0,81 & - & - & - & - & - & 0,89 & 0,90 & - & 0,73 & 1,00 & & & & & \\
\hline Alcal. & 0,86 & - & - & 0,96 & 0,90 & - & 0,90 & - & 0,95 & - & - & 0,82 & - & 0,89 & 0,65 & 0,99 & 0,71 & 1,00 & & & & \\
\hline $\mathrm{pH}$ & - & - & - & 0,79 & - & - & - & 0,83 & - & - & - & - & - & - & - & - & - & - & 1,00 & & & \\
\hline STD & 0,86 & 0,78 & - & 0,99 & 0,85 & - & - & - & 0,78 & - & - & 0,90 & 0,87 & 0,88 & - & 0,93 & - & 0,95 & - & 1,00 & & \\
\hline CE & 0,82 & 0,74 & - & 0,96 & 0,81 & 0,79 & - & 0,90 & 0,79 & - & - & 0,86 & 0,86 & 0,86 & - & 0,90 & - & 0,93 & 0,72 & 0,99 & 1,00 & \\
\hline $\mathrm{T}^{\circ} \mathrm{C}$ & - & - & - & - & - & - & - & - & - & - & - & - & - & - & - & - & - & - & - & - & - & 1,00 \\
\hline
\end{tabular}

- abaixo do nível de significância 
As boas correlações do STD e CE com os elementos $\mathrm{Ca}, \mathrm{Mg}$, $\mathrm{Mn}, \mathrm{K}$ e Na e com os ânions $\mathrm{HCO}_{3}^{-} \mathrm{e} \mathrm{NO}_{3}^{-}$, na época seca $(\mathrm{R}=0,74$ a 1,00$)$ e chuvosa $(\mathrm{R}=0,78$ a 0,99$)$ nas águas da BHRD e a correlação $(\mathrm{R}=0,87$ a 0,93$)$ entre $\mathrm{NH}_{4}^{+}$com $\mathrm{SO}_{4}^{2-}, \mathrm{PO}_{4}^{3-}, \mathrm{Cl}^{-}, \mathrm{NO}_{3}^{-}, \mathrm{P}, \mathrm{Na}$, $\mathrm{Ca}$ e $\mathrm{K}$, na época seca sugerem a contribuição das atividades domésticas e/ou rurais na bacia.

Fosfato correlaciona-se positivamente com os elementos $\mathrm{Ca}$, $\mathrm{Al}, \mathrm{Na}, \mathrm{P}$ e K na época seca, e com $\mathrm{Sr}$, Ca e K na chuvosa. Isso sugere sua adsorção às argilas, já que na maioria das amostras analisadas não foi detectado esse composto.

Cálcio é o único elemento que possui correlação $(R=0,67) \mathrm{com}$ a temperatura, na época seca. Os elementos $\mathrm{Al}$ e Fe correlacionamse com a condutividade na época chuvosa, e somente o $\mathrm{Al}$ com o pH mostram, desta forma, o intemperismo na área, associado principalmente aos aspectos relacionados com a ocupação humana na área.

Na época seca observa-se mais claramente a boa correlação dos elementos e compostos $\left(\mathrm{P}, \mathrm{Na}, \mathrm{K}, \mathrm{NO}_{3}^{-}, \mathrm{SO}_{4}^{2-}, \mathrm{PO}_{4}^{3-}, \mathrm{HCO}_{3}^{-} \mathrm{e}\right.$ $\mathrm{NH}_{4}^{+}$) que na época chuvosa. Assim, a influência de áreas urbanas é maior na seca.

Correlacionando-se turbidez e cor com íons em cada época (Tabela 9), verifica-se que existe uma boa correlação entre eles apenas na época seca. Isso mostra a possível contribuição da área urbana para estes parâmetros nesta época.

\section{Avaliação da água na BHRD}

Esta avaliação objetiva visualizar mais explicitamente as condições da água na entrada e saída do Rio Descoberto no DF e identificar as possíveis fontes antrópicas.
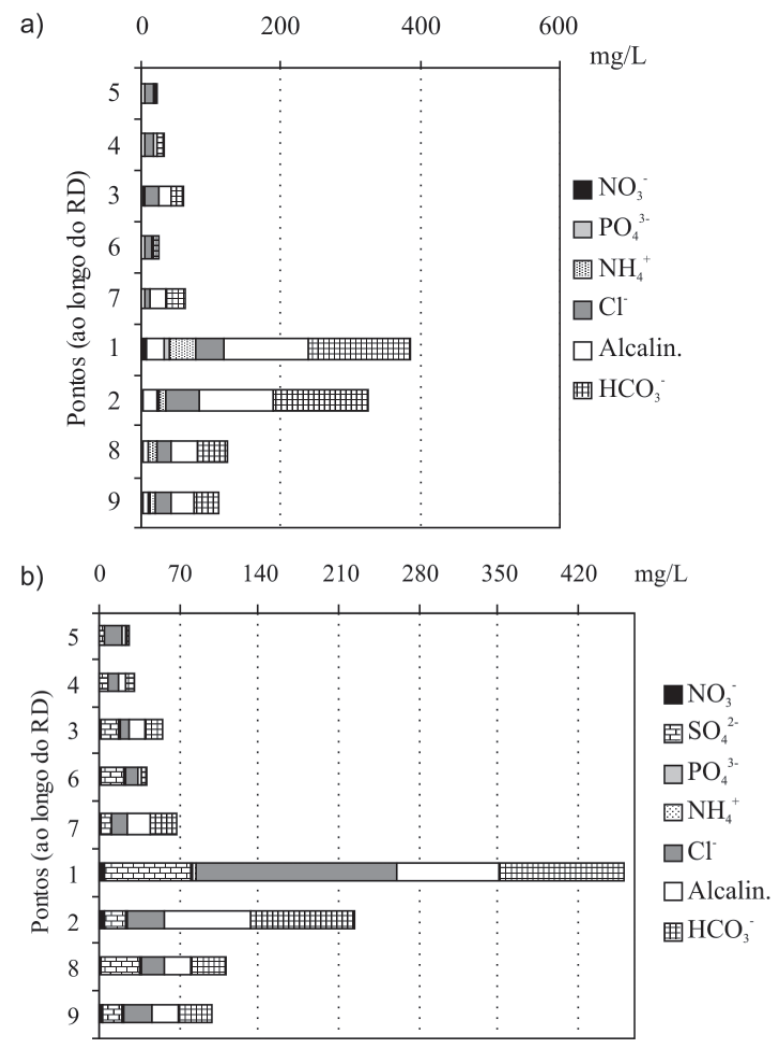

Tabela 9. Correlação Spearman (R) da turbidez e cor com outros parâmetros nas duas épocas climáticas (correlações $\mathrm{p}<0,05$ )

\begin{tabular}{|c|c|c|c|c|c|c|c|}
\hline \multicolumn{8}{|c|}{ Época seca } \\
\hline & $\mathrm{NO}_{3}^{-}$ & $\mathrm{SO}_{4}^{2-}$ & $\mathrm{HCO}_{3}^{-}$ & $\mathrm{NH}_{4}^{+}$ & $\mathrm{Cl}^{-}$ & $\mathrm{PO}_{4}{ }^{3-}$ & Cor \\
\hline cor & 0,87 & 0,94 & 0,85 & 0,88 & 0,67 & 0,77 & - \\
\hline turbidez & 0,87 & 0,94 & 0,98 & 0,88 & 0,77 & 0,77 & 0,87 \\
\hline \multicolumn{8}{|c|}{ Época chuvosa } \\
\hline cor & - & - & - & - & - & - & - \\
\hline turbidez & 0,78 & - & - & - & - & - & - \\
\hline
\end{tabular}

- = abaixo do nível de significância

A Figura 2 mostra os parâmetros cor, turbidez, temperatura, alcalinidade, $\mathrm{NH}_{4}^{+} \mathrm{e} \mathrm{pH}$ e os ânions $\mathrm{Cl}, \mathrm{HCO}_{3}^{-}, \mathrm{SO}_{4}^{2-}, \mathrm{PO}_{4}^{3-}$ e $\mathrm{NO}_{3}^{-}$. Observa-se que o $\mathrm{pH}$ e a temperatura não variam muito ao longo da bacia nas duas épocas, ao contrário da cor, turbidez, alcalinidade, $\mathrm{NH}_{4}^{+}$e dos ânions.

As concentrações elevadas de $\mathrm{Cl}^{-}, \mathrm{HCO}_{3}^{-}, \mathrm{NO}_{3}^{-}$e $\mathrm{NH}_{4}^{+}$, nos pontos 1 e 2, provêm de despejos de esgotos domésticos da cidade de Taguatinga.

$\mathrm{Na}$ avaliação dos elementos-traço e maiores na água, ao longo da bacia (Figura 3), os elementos Y, Ti, V, Ni, Zr, Cu, Cr, Ba, Co e Zn foram excluídos nas duas épocas por apresentarem concentrações muito baixas e/ou abaixo do limite de detecção. La, Cd, Al e Mn foram somente considerados na época chuvosa.

$\mathrm{Na}$ Figura 3 percebe-se, ainda, que os elementos $\mathrm{Ca}, \mathrm{Mg}, \mathrm{P}, \mathrm{Na}$ e K, tanto na época seca quanto chuvosa, são provenientes de esgotos já que suas concentrações tendem a aumentar principalmente

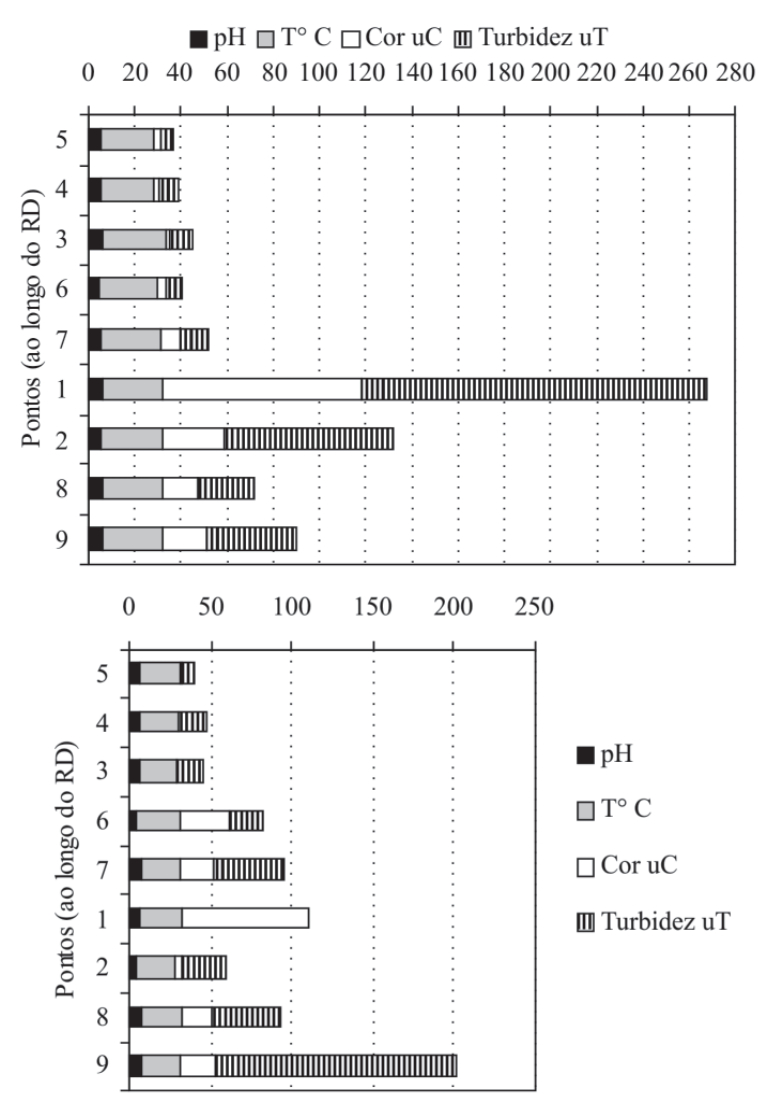


a)

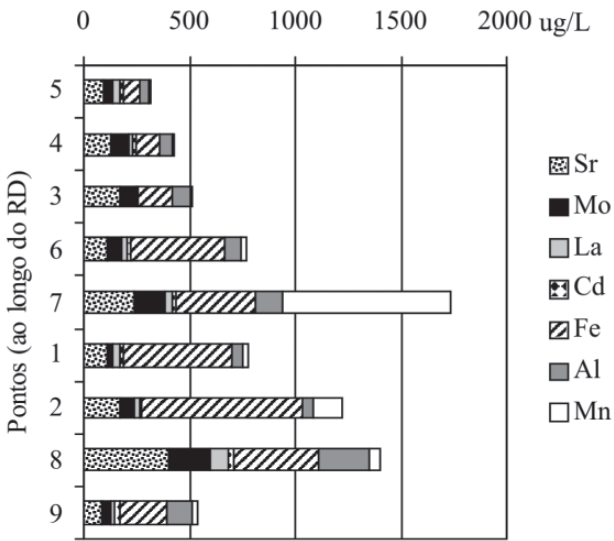

b)

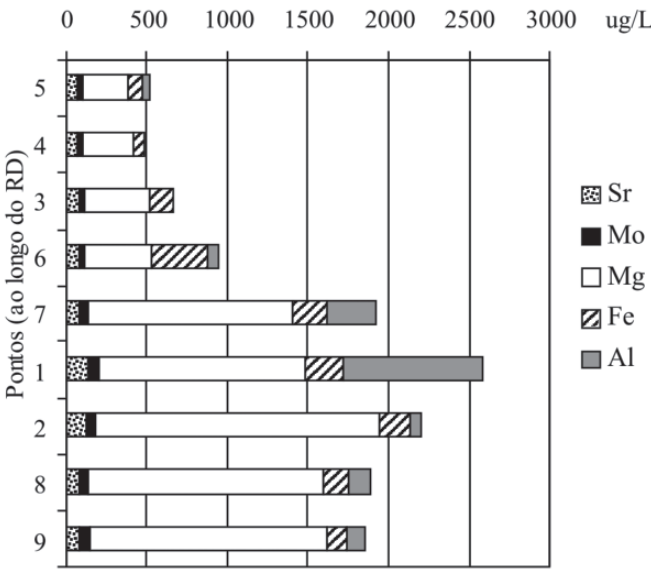

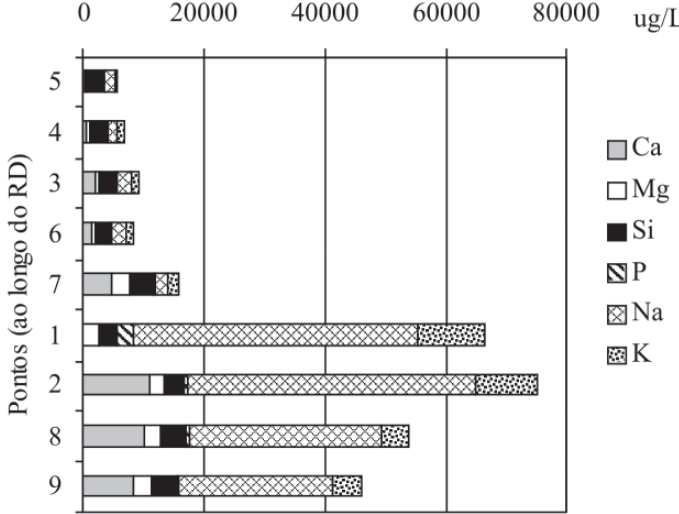

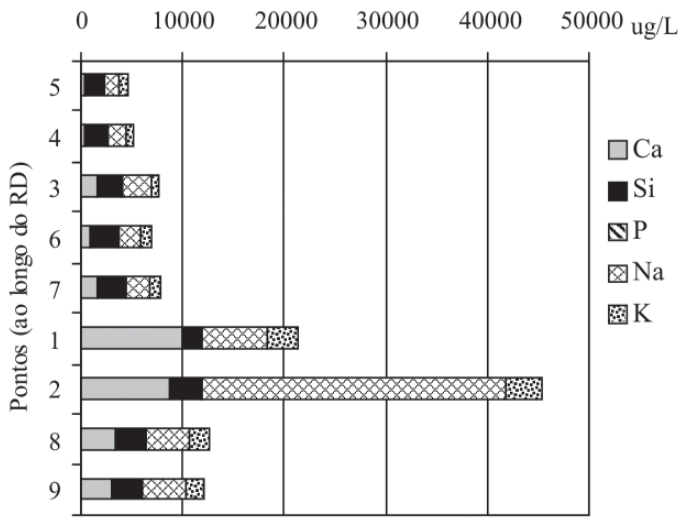

Figura 3. Distribuição dos elementos-traço e maiores ao longo da Bacia Hidrográfica do Rio Descoberto: a) época seca e b) chuvosa

no ponto 2 (épocas seca e chuvosa) e, devido à própria diluição, a concentração diminui nos pontos 8 e 9, também nas duas épocas.

Quanto ao valor "outlier" de Mn no ponto 7, (época seca - Tabela 5), que pode ser proveniente da cidade de Santo Antônio do Descoberto, influencia os pontos 8 e 9 , assim como os resultados de Fe e Al.

Os elementos-traço e maiores (Tabela 3) mostram uma variação significativa ao longo da bacia, principalmente nos pontos $1 \mathrm{e}$ 2 e nos pontos após a foz do Rio Melchior (8 e 9), influenciados pela rápida diluição nos pontos 1 e 2 .

$\mathrm{Na}$ direção do fluxo do Rio Descoberto $(\mathrm{N}-\mathrm{S})$, percebe-se que na entrada do DF as concentrações dos elementos $\mathrm{Sr}, \mathrm{Mo}, \mathrm{La}, \mathrm{Cd}$, $\mathrm{Fe}, \mathrm{Al}, \mathrm{Mn}, \mathrm{Mg}, \mathrm{Si}, \mathrm{Ca}, \mathrm{P}, \mathrm{K}$ e Na são baixas, tendendo a aumentar nos pontos localizados na entrada do lago (3 e 4), área do INCRA. Após o lago, o teor de alguns elementos e compostos aumenta bastante, principalmente nos pontos localizados próximos de áreas urbanas e/ou agrícolas (1, 2 e 7). Na saída do DF (pontos 8 e 9), a própria diluição do rio faz com que as concentrações tendam a diminuir, ou seja, a qualidade da água é influenciada nos pontos específicos.

\section{CONCLUSÕES}

Esta pesquisa, desenvolvida na extensão da Bacia Hidrográfica do Rio Descoberto nas épocas seca e chuvosa, mostrou primeiramente que estas águas se enquadram, segundo o CONAMA, na classe 4 destinada à navegação, por apresentarem teores de níquel maiores que $25 \mu \mathrm{g} \mathrm{L}^{-1}$. Verificou-se também que existe uma variação na concentração de alguns parâmetros físico-químicos, ele- mentos-traço e maiores com a mudança climática. As elevadas concentrações (localizadas principalmente em áreas agrícolas e urbanas) registradas, como alcalinidade, turbidez, cor, $\mathrm{PO}_{4}^{3-}, \mathrm{NO}_{3}^{-}$, $\mathrm{NH}_{4}^{+}, \mathrm{Cl}^{-}$e $\mathrm{SO}_{4}^{2-}$ e dos elementos $\mathrm{P}, \mathrm{Mn}, \mathrm{Ba}, \mathrm{Na}, \mathrm{K}, \mathrm{Ni}$ e $\mathrm{Sr}$, são diluídas ao longo do percurso até a foz no rio. Isso minimiza, por enquanto, a possibilidade de ocorrerem problemas que venham a comprometer a qualidade da água deste manancial. Os resultados obtidos nas análises de alcalinidade, fosfato e amônia nas épocas estudadas apresentaram-se acima da média de outros estudos no DF, indicando a influência de efluentes domésticos e explicita o possível comprometimento da qualidade do manancial, embora o pH não sofra grandes variações.

As altas concentrações de $\mathrm{Ca}$ podem estar relacionadas a lentes calcárias do Grupo Paranoá juntamente com a influência antrópica, principalmente associada à atividade agrícola, visto que o Ca se correlaciona com a maioria dos elementos e ânions.

A análise de correlação não paramétrica de Spearman permitiu visualizar a correlação entre espécies químicas e parâmetros físico-químicos determinados nas águas da BHRD com indicação de origem semelhante - produto da urbanização desordenada e utilização indiscriminada de fertilizantes em áreas de agricultura.

Assim, é necessário o monitoramento desses parâmetros e espécies químicas, a fim de controlar os valores reais com os valores estabelecidos pelo CONAMA, além da instalação de uma estação de tratamento de efluentes domésticos nas cidades de Taguatinga, Samambaia e Ceilândia, pois este manancial responde por grande percentual de atendimento no abastecimento público do DF. 


\section{AGRADECIMENTOS}

À CAPES (Coordenação de Aperfeiçoamento de Pessoal de Nível Superior), pela concessão de bolsa de mestrado no período de 09/1999 à 09/2001, e ao CNPq- Processo 300295/96-0.

\section{REFERÊNCIAS}

1. Ribeiro, M. O.; Koide, S.; Souza, M. A. A.; Resumos do $1^{o}$ Simpósio de Recursos Hídricos do Centro-Oeste, Brasília, Brasil, 2000.

2. Boaventura, G. R.; Souza, R. S.; Pontes, C. H. C; Pinelli, M. P.; Resumos Expandidos do $7^{\circ}$ Congresso Brasileiro Geoquímico e $5^{\circ}$ Congresso Geoquímico dos Países de Língua Portuguesa, Porto Seguro, Brasil, 1999.

3. Boaventura, G. R.; Brito, V. E. B.; Bispo, R. S.; Revista da Escola de Minas 1998, 51, 57.

4. Carvalho Jr., O. A. C; Boaventura, G. R.; Martins, E. S.; Pereira, F. J.; Brito, V. E. B.; Bispo, R. S.; Revista da Escola de Minas 1998, 51, 47.

5. Boaventura, G. R.; Relatório Final FAPDF/FINATEC, 1997.

6. Boaventura, G. R.; Relatório Final WWF/FINATEC, 1997.

7. Skinner, J. A.; Lewia, K. A.; Bardon, K. S.; Tucker, P.; Catt, J. A.; Chamber, B. J.; J. Environ. Manag. 1997, 50, 111.

8. Bahri, A.; Water Res. 1998, 32, 3484.

9. Freitas, M. I. C.; Silva, R. N. M.; Rodrigues, E. E.; Filho, O. C.; Pereira, J.; Gedeon, A. D.; Mendes, J. L. P.; Fernandes, J. R. R.; Resumos do $27^{\circ}$ Congresso Interamericano de Engenharia Sanitária e Ambiental, Rio Grande do Sul, Brasil, 1999.

10. Carvalho, A. R.; Schlittler, F. H. M.; Tornisielo, V. L.; Ouim. Nova 2000, 23,618 .

11. Dores, E. F. G. C.; De-Lamonica-Freire, E. M.; Quim. Nova 2001, 24, 27.

12. Tarvainen, T.; Lahermo, P.; Mannio, J.; Water, Air, Soil Pollut. 1997, 94, 1.

13. Yabe, M. J. S.; Oliveira, E.; Quim. Nova 1998, $21,551$.

14. Souza, A. D. G.; Tundisi, J. G.; Rev. Bras. Biol. 2000, 60, 563.

15. CAESB- Companhia de Água e Esgoto de Brasília; Relatório Interno, Brasília, 1999.
16. Brito, F. A.; Dissertação de Mestrado, Universidade de Brasília, Brasil, 1999.

17. Falcomer, J.; Dissertação de Mestrado, Universidade de Brasília, Brasil, 1994.

18. Rêgo, M. C. A. M.; Dissertação de Mestrado, Universidade de Brasília, Brasil, 1997.

19. Campos, J. G. E.; Freitas, F. H. S; Inventário Hidrológico e dos Recursos Hídricos Superficiais do Distrito Federal. Relatório Técnico, Hidrogeologia do Distrito Federal, IEMA/ UnB: Brasília, 1998, vol. IV.

20. Andrade, F. S.; Dissertação de Mestrado, Universidade de Brasília, Brasil, 1999.

21. Embrapa; Levantamento de Reconhecimento dos solos do Distrito Federal. Boletim técnico, $\mathrm{n}^{\circ}$ 53, SNLCS: Rio de Janeiro 1978.

22. CAESB; Relatório Interno Plano de Proteção do Lago Descoberto, 1985.

23. Pinto, M. N.; Neves, R. R.; Geociências 1985, 4, 127.

24. Agudo, E. G.; Guia de Coleta e Preservação de Amostras de Água, CETESB: São Paulo, 1987.

25. Förstner, U.; Salomons, W.; Environ. Technol. Lett. 1980, 1, 494.

26. APHA; AWWA; WPCF; Standard Methods for the Examination of Water and Wastewater; Clescerl, L. S.; Greenberg, A. E.; Eaton, A. D., eds.; $20^{\mathrm{a}}$ ed., American Public Health Association: Washington, 1999.

27. Sawyer, C. N.; Mcccarty, P. L.; Parkin, G. N.; Chemistry for Environmental Engineering, 4a ed., McGraw-Hill: Cingapura, 1994.

28. Conama; Resolução CONAMA $n^{\circ} 20$ de junho de 1986.

29. Szikszay, M. L. S.; Min. Met. 1969, 297, 133.

30. Szikszay, M. L. S.; Boletim IG-USP 1973, 4, 97.

31. Esteves, F. D. A.; Fundamentos de Limnologia, FINEP: Rio de Janeiro, 1988

32. Rocha, J. C.; Hirche, R. N.; Eclética Química 1994, 19, 105.

33. Brasil. Ministério da Saúde. Portaria n 1469 de 29 de dezembro de 2000; Normas de Qualidade da Água para Consumo Humano. Republicada no DO no 1 -E de 02/01/2001e no DO n ${ }^{\circ} 7$-E de 10/01/2000.

34. Durum, W H.; Haffty, J.; Geochim. Cosmochim. Acta 1963, 27, 1. 